\title{
GESTÃO AMBIENTAL E MUDANÇA ORGANIZACIONAL: UM ESTUDO LONGITUDINAL (1971-2009) EM UMA COMPANHIA DE SANEAMENTO BRASILEIRA
}

\author{
Tatiana Gomes Carvalho Rocha de Matos \\ Mestre em Administração pela UDESC/ESAG \\ tati.rochamatos@gmail.com \\ Paula Chies Schommer \\ Doutora em Administração de Empresas pela FGV/EAESP \\ Professora do Departamento de Administração Pública do PPGA/ESAG/UDESC \\ paulacs3@gmail.com
}

\begin{abstract}
RESUMO
Em meio às constantes influências advindas do ambiente interno e externo, as organizações vivenciam mudanças que podem alterar processos, valores, políticas e estruturas. A atual preocupação com a preservação ambiental e o desenvolvimento sustentável tende a influenciar mudanças organizacionais, especialmente em certos setores, como o de saneamento básico. Empresas de abastecimento de água e coleta e tratamento do esgoto são potencialmente sensíveis à necessidade de adotar premissas e instrumentos de gestão ambiental, dada a relação direta entre sua atuação e a qualidade do meio ambiente. Este estudo busca compreender as mudanças organizacionais em gestão ambiental ocorridas na Água Azul, principal empresa de saneamento de um estado brasileiro, entre os anos de 1971 e 2009, considerando as dimensões de contexto - em que condições do contexto interno e externo as mudanças ocorreram; conteúdo - quais mudanças ocorreram e; processo - como as mudanças ocorreram. Esta pesquisa, de natureza qualitativa, estuda um caso único, investigado de modo longitudinal, exploratório e descritivo, examinando as mudanças organizacionais ocorridas em quatro períodos. Orientada pelas dimensões de contexto, conteúdo e processo, do modelo contextualista de Pettigrew (1987), e categorizações de gestão ambiental, elaboradas por Barbieri (2007), Jabbour e Santos (2006) e Donaire (1995), os dados foram coletados e tratados por meio da abordagem da direct research. Conclui-se que, embora as mudanças em gestão ambiental nos períodos analisados sejam visíveis em iniciativas e áreas específicas da empresa, essas transformações correspondem a estágios iniciais ou intermediários, não sendo algo disseminado e incorporado nas práticas da organização.
\end{abstract}

Palavras-chave: Desenvolvimento sustentável; Gestão ambiental; Mudança organizacional; Saneamento.

\section{ENVIRONMENTAL MANAGEMENT AND ORGANIZATIONAL CHANGE: A LONGITUDINAL STUDY (1971-2009) IN A BRAZILIAN SANITATION COMPANY}

\begin{abstract}
Amid the constant influences that arise from both the internal and external environment, organizations experience changes that may alter their processes, values, policies, and structures. The current preoccupation with environmental conservation and sustainable development has tended to influence organizational changes, especially in certain sectors, such as basic sanitation. Given the direct relationship between their operation and the quality of the environment, companies that supply water and collect and treat sewage are potentially sensitive to the need to adopt environmental management premises and instruments. This study aims to understand the organizational changes in environmental management that occurred between 1971 and 2009 in Água Azul - the principal sanitation company in a Brazilian state - taking into consideration the dimensions of context: the conditions of internal and external context in which changes occur; content: what changes actually occur and; process: how these changes occur. The research is a qualitative single case study using longitudinal, exploratory, and descriptive methods to examine the organizational changes that occurred over four time periods. Guided by the dimensions of context, content, and process from Pettigrew's (1987) contextualized model, and environmental management categorizations from Barbieri (2007), Jabbour and Santos (2006), and Donaire (1995), data collection and analysis was conducted using the direct research approach. We concluded that, although there were visible changes in the environmental management of specific initiatives and areas of the company during the analyzed periods, those related to initial or intermediary stages were not disseminated or incorporated into the organization's practices.
\end{abstract}

Key words: Environmental management; Organizational change; Sanitation; Sustainable development. 


\section{INTRODUÇÃO}

A compreensão da natureza das mudanças organizacionais, seus influenciadores, as características de seus processos e suas consequências sobre as práticas e as relações organizacionais é relevante tanto para a prática quanto para a pesquisa em gestão (Hernandes \& Caldas, 2001).

Entre os modelos de análise que permitem explorar os elementos que compõem o processo de mudança, está o modelo contextualista e processual de Pettigrew (1987), por meio do qual as mudanças organizacionais são analisadas tendo como base elementos relativos às dimensões do conteúdo (o que mudou), do contexto (porque mudou) e do processo (como mudou). Esse modelo permite observar que as organizações são sistemas nos quais as mudanças ocorrem continuamente, a partir de ações interdependentes e eventos que se relacionam constantemente e são construídos ao longo do tempo (Alperstedt, 2000). Para Pettigrew (1987), não há como compreender a mudança, a partir de uma visão restrita, que não considere a temporalidade contínua entre eventos do passado, do presente e do futuro.

Isso é visível quando se busca compreender mudanças organizacionais ocorridas por necessidades e obrigações inseridas mais recentemente no universo organizacional, influenciadas por elementos históricos particulares. É o caso das mudanças provocadas pelo surgimento da preocupação com a preservação ambiental e com o desenvolvimento sustentável, que coloca o meio ambiente como variável a ser considerada na gestão. As discussões sobre meio ambiente ganharam espaço a partir da década de 1960, quando se percebeu, em círculos de especialistas e de comunidades afetadas pelos problemas ambientais, que o desequilíbrio no uso de recursos ambientais poderia conduzir à degradação da qualidade de vida e até à destruição do planeta (Barbieri, 2007; Nobre e Amazonas, 2002).

No âmbito organizacional, essa percepção é mais recente e se traduziu, em certas organizações, na busca da incorporação de premissas e ações gerenciais que contribuam para o desejado equilíbrio entre desenvolvimento econômico e meio ambiente (Schenini, 2005), além de considerar elementos sociais, completando o chamado tripé do desenvolvimento sustentável ambiental, econômico e social. Em meio a esse processo de construção do desenvolvimento sustentável, premente na atualidade (Nobre e Amazonas, 2002), as empresas ocupam papel central (Barbieri, 2007), algumas delas adotando sistemas de gestão ambiental, ou seja, diretrizes e atividades administrativas e operacionais com o objetivo de reduzir efeitos negativos e gerar efeitos positivos sobre o meio ambiente (Barbieri, 2007; Schenini, 2005).

Em meio a essa dinâmica de mudança organizacional em prol do equilíbrio entre aspectos econômicos, sociais e ambientais, estão empresas que atuam no setor de saneamento básico. Se as atividades das empresas desse setor produzem efeitos ambientais positivos na sociedade, uma vez que distribuem água potável e coletam e tratam o esgoto, por outro, podem causar impactos negativos no meio ambiente, por exemplo, pelo uso de produtos químicos, esgotos lançados nos rios, desmatamento, geração de lodo e resíduos dos sistemas de tratamento (Filho, Abreu \& Fernandes, 2008). Ante as características dos serviços de saneamento básico, espera-se que as organizações que atuam nesse setor apliquem a gestão ambiental em suas operações, inclusive pela necessidade de aprovação dos projetos mediante processos de licenciamento ambiental (Filho, Abreu \& Fernandes, 2008).

Diante da relevância do meio ambiente para organizações que lidam diretamente com água e esgoto, afigura-se importante que a gestão ambiental de tais empresas seja caracterizada, a fim de se compreender quais mudanças organizacionais vêm realizando para se aproximarem do propósito de levar saúde à população, proteger o meio ambiente e promover o desenvolvimento sustentável. Há que considerar que empresas de saneamento são afetadas por diversas pressões e interesses políticos e mercadológicos de seu segmento de atuação empresarial e de cada contexto local em que operam, algo estreitamente relacionado ao histórico das políticas desse setor no país.

Em um dos estados brasileiros, a empresa aqui chamada Água Azul é a principal 
responsável pelo saneamento básico, prestando serviços de abastecimento de água e coleta e tratamento de esgoto para mais de dois milhões de pessoas. Em razão da relevância da empresa em seu contexto de atuação e pelo interesse em investigar como executa a gestão ambiental, considerando a responsabilidade ambiental que lhe é imputada nessa área de atuação, interessou-nos analisar como ela vem se modificando, desde sua fundação até a época atual, para atender aos anseios e às cobranças advindas da legislação e dos grupos de pressão, tais como sociedade, mídia e órgãos ambientais. Foi realizado, pois, um estudo de caso, durante o ano de 2010, no âmbito do qual se define o objetivo geral deste trabalho: compreender as mudanças organizacionais em gestão ambiental ocorridas na Água Azul entre os anos de 1971 e 2009, considerando as dimensões do contexto, do conteúdo e do processo das mudanças. Os objetivos específicos associados são: a) levantar em que condições as mudanças ocorreram, ou seja, o contexto interno e o contexto externo; b) identificar quais mudanças ocorreram, o conteúdo; c) descrever como as mudanças ocorreram, o processo.

O recurso básico para análise das mudanças ocorridas na empresa é o modelo contextualista de Pettigrew (1987), que contempla contexto, conteúdo e processo de mudança. A coleta, o tratamento e a análise dos dados foram ancoradas na direct research (Mintzberg, 1979; Mintzberg \& Mchough, 1985) e na abordagem longitudinal de análise da evolução da organização ao longo de um determinado período histórico. Para análise da gestão ambiental em cada período, utilizaram-se como referências as classificações elaboradas por Barbieri (2007), Jabbour e Santos (2006) e Donaire (1995), que identificam diferentes abordagens ou estágios das práticas de gestão ambiental nas organizações. Esses referenciais de análise serão detalhados adiante, seguidos da apresentação de dados sobre a empresa e sua análise, chegando-se às conclusões do estudo.

\section{MUDANÇA ORGANIZACIONAL E GESTÃO AMBIENTAL NO SETOR DE SANEAMENTO}

Uma vez que se busca compreender mudanças organizacionais em gestão ambiental em uma empresa de saneamento básico, iniciaremos fazendo breve revisão teórica sobre mudança organizacional e apresentaremos um modelo para sua compreensão. Em seguida, definiremos a gestão ambiental e indicaremos tipologias que permitem sua análise, bem como dados gerais sobre empresas de saneamento básico no país.

\subsection{Mudança organizacional}

As primeiras teorizações organizacionais consideravam as organizações como sistemas fechados, com fronteiras fixas e sem abertura para o ambiente externo. O que se passava fora da organização não recebia muita atenção ou sequer era considerado nas análises, o que tornava tais teorias insuficientes para explicar fenômenos que ocorriam internamente e tinham relação com transformações sociopolíticas e econômicas mais amplas (Clegg, 1998; Andion \& Serva, 2006; Mello, 1997).

A partir da década de 1950, os estudos organizacionais passaram a incorporar a teoria geral dos sistemas e começaram a considerar a organização como uma classe especial de sistema aberto e complexo, no qual os elementos estão em contínua interação e intercâmbio com o ambiente, por meio do fluxo de entradas e saídas (Clegg, 1998). Os estudos organizacionais passaram, então, a dedicar atenção à complexidade das organizações, na tentativa de explicar as múltiplas dimensões organizacionais e sua interação e adaptação às mudanças no ambiente externo (Bertalanffy, 1977; Clegg, 1998; Katz \& Kahn, 1987; Andion \& Serva, 2006; Mello, 1997). Com base em teorias organizacionais surgidas desde então, considera-se o ambiente como elemento fundamental na análise das organizações, particularmente quando se deseja compreender as mudanças organizacionais.

Ressalta-se que esta noção de ambiente refere-se ao âmbito organizacional e institucional, diferente do uso do termo na expressão meio ambiente, que se refere ao conjunto de condições, leis, 
influências e interações de ordem física, química e biológica que permite, abriga e rege a vida em todas as suas formas (Brasil, 1981).

O ambiente organizacional, por sua vez, pode ser entendido como o conjunto de fatores físicos e sociais internos e externos considerados na tomada de decisões pelos indivíduos da organização. Embora as fronteiras organizacionais, ou os limites entre o ambiente interno e externo, não sejam sempre evidentes, podemos considerar, idealmente, que o ambiente interno é composto por fatores físicos e sociais que estão dentro dos limites organizacionais, enquanto o ambiente externo consiste em fatores físicos e sociais presentes além da fronteira da organização (Duncan, 1972).

No cruzamento entre os elementos internos e externos, percebe-se o quão complexo é o fenômeno da mudança organizacional (Mintzberg \& Westley, 1992), a qual pode ser entendida como o conjunto de transformações capazes de gerar impacto na organização como um todo ou em partes (Wood Jr., 1995). Tais transformações podem ser de natureza estrutural, estratégica, cultural, tecnológica ou humana, entre outras e podem ser decorrentes de diversas influências, tais como conflitos, equívocos, tensões e desequilíbrios internos, inovação e aprendizagem, novas leis ou regulamentações, alterações tecnológicas, variações nos valores e preferências de lideranças, parceiros ou clientes, necessidade de melhoria da qualidade, aumento da produtividade e redução de custos face à competitividade (Hernandes \& Caldas, 2001; Wood Jr., 1995; Katz \& Kahn, 1987).

Robbins (2006) considera a mudança organizacional como algo intencional e direcionado ao alcance de metas. Grey (2004) e compartilha dessa visão, e vai além ao afirmar que as mudanças são decorrentes das próprias ações da organização e não são respostas que elas precisam dar a algo ou alguém. Neste contexto, Wood Jr. (1995) considera duas possibilidades: mudanças reativas, realizadas na organização em resposta às mudanças do ambiente externo; ou voluntárias, quando feitas, por exemplo, para antecipar-se à concorrência.

Seja ela intencional ou não, a complexidade que caracteriza a mudança organizacional não permite que sua compreensão ocorra sob a orientação de paradigmas mecanicistas (Feuerschütte, 1997) e unidimensionais, muito menos por meio de visões que a caracterizam como necessariamente vinculadas ao processo de globalização e à alta tecnologia ou a ambientes instáveis com altas taxas de mudanças e de competição acirrada, que as obriga a adotarem medidas modificadoras para sobreviver (Grey, 2004). Essas premissas sobre as organizações, chamadas por Grey (2004) de "fetiche da mudança", precisam ser desmistificadas, segundo o autor, por considerarem que as organizações mudam apenas para responder às mudanças globais aceleradas, sem considerar outros elementos, tais como as pessoas, as relações, o contexto político local, a legislação e outros aspectos que as provocam. Afinal, conforme observa Pettigrew (1987), no processo de mudança organizacional estão inseridas as ações, reações e interações organizacionais e intraorganizacionais que contemplam a temporalidade contínua entre passado e futuro. Para Grey (2004), a temporalidade, por si só, é motivo gerador de mudança, pois esta é suscetível ao caráter inevitável do tempo. Simplesmente pelo passar do tempo a mudança está ocorrendo. Weick e Quinn (1999), no mesmo sentido, observam a mudança como aspecto inerente à organização, num processo constante e contínuo em que não se sabe quando começa, porque nunca pára.

Considerando essa temporalidade, Pettigrew (1990) elaborou um modelo com o intuito de codificar e organizar a aprendizagem para os que pretendem efetuar estudos longitudinais de processos de mudança. O objetivo do chamado modelo contextualista é explorar a aleatória, complexa e, por vezes, contraditória maneira como a mudança surge, e construir um recurso que permita a apreciação dos conflitos racionais, objetivos e comportamentais. O desafio percebido pelo autor é a construção de um modelo que supere visões tradicionais sobre mudança, que, em sua maioria, consideram as ações como ordenadas e sequenciadas, de modo a atingir fins racionalmente declarados e nas quais os atores se comportam de maneira mecânica e altruísta na busca dos objetivos organizacionais. Pettigrew (1987) oferece parâmetros para relacionar conteúdo, contexto e processos de mudança ao longo do tempo, considerando que o contexto não é apenas um ambiente de estímulo, mas um arranjo de estruturas e processos em que as interpretações subjetivas dos atores 
ao perceber, compreender, aprender e lembrar ajudam a moldar o processo. Em síntese, na concepção do modelo contextualista e processual de Pettigrew (1987), a mudança organizacional deve ser estudada em três dimensões: contexto, que é o "porque" ocorreu a mudança; conteúdo, que mostra "o que" mudou; processo, que explica "como" mudou.

\subsection{Gestão ambiental}

Na medida em que a questão ambiental é considerada não um modismo, mas sim algo crucial e irreversível, uma tendência que se observa em diversas organizações é a procura de instrumentos e sistemas de gestão ambiental (Donaire, 1995 ; Guimarães, 1995). Seja por força de pressões sociais e legais, pela mudança de padrões culturais ou pela percepção de que investimentos em proteção ambiental podem representar vantagem competitiva (Donaire, 1995; Schenini, 2000; Campos \& Melo, 2008), a gestão ambiental vem se consolidando nas últimas décadas, embora não de modo homogêneo entre regiões e entre setores produtivos.

Para Schenini (2005) e Valle (1995), a gestão ambiental é um conjunto de ações ou medidas adotadas pelas organizações que buscam obter vantagens decorrentes do desenvolvimento sustentável, que deve ser constituída de um planejamento ambiental que apresente diretrizes orientadas não apenas por aspectos legais, mas também pela busca de melhorias ambientais. Barbieri (2007) entende gestão ambiental como diretrizes e atividades administrativas e operacionais realizadas com o objetivo de obter efeitos positivos sobre o meio ambiente. Ou, como percebe Dias (2009), para se evitar, na medida do possível, problemas com o meio ambiente. Para Dias (2009), a gestão ambiental é o principal instrumento para se obter um desenvolvimento organizacional sustentável. Para implementá-la é preciso que a organização empregue um Sistema de Gestão Ambiental (SGA) que a auxilie a sistematizar as responsabilidades organizacionais, os procedimentos, processos e os objetivos definidos em sua política ambiental, de maneira a levá-la a atingir e manter-se em funcionamento de acordo com os preceitos do desenvolvimento sustentável (Dias, 2009).

Um Sistema de Gestão Ambiental implantado e operado de maneira eficaz, segundo Barbieri (2007), possibilita à organização a obtenção de melhores resultados com menos recursos, em decorrência de ações planejadas e coordenadas, servindo de instrumento para que a organização alcance os objetivos da gestão ambiental. O SGA requer formulação de diretrizes, definição de objetivos, coordenação de atividades e avaliação de resultados (Barbieri, 2007) e pode ser útil no gerenciamento e controle das ações da empresa sobre o meio ambiente, na tomada de decisão e no alinhamento dos objetivos e metas ambientais com as estratégicas. A eficácia da gestão ambiental, para Campos e Melo (2008), depende da incorporação de um sistema de medidas que monitore continuamente indicadores de desempenho ambiental.

Schenini (2005) adverte que, ao adotar a gestão ambiental, as organizações devem, primeiramente, conhecer e adequar-se às regras impostas pela legislação, já que estão duplamente sujeitas aos rigores da lei: para operar em certas áreas precisam apresentar estudos, análises e licenciamentos que são exigidos; via fiscalização, podem ser punidas caso não cumpram as obrigações que lhes são impostas. Moura (2002) observa que a legislação ambiental brasileira contempla um amplo conjunto de dispositivos legais que definem atribuições, obrigações e responsabilidades dos empreendedores e do poder público nas esferas municipal, estadual e federal. Barbieri (2007) lembra que, até a década de 1980, a legislação ambiental abordava o meio ambiente de modo segmentado. Até então, os problemas ambientais eram regulados de modo separado em solo, água, florestas, recursos minerais e outros. O autor explica que, somente no início da década de 1980, a legislação começou a considerar os recursos naturais como interdependentes e procurou integrar as ações governamentais em uma abordagem sistêmica.

A Constituição Federal de 1988 dedicou o Capítulo VI para tratar do meio ambiente e incorporou na redação do art. 225 o conceito de desenvolvimento sustentável. No parágrafo $1^{\circ}$, inciso IV desse art. 225, a Constituição incumbe ao poder público exigir o estudo prévio de impacto

Revista de Gestão Social e Ambiental - RGSA, São Paulo, v. 7, n. 2, p. 20-36, maio/ago. 2013. 
ambiental para instalação de obra ou atividade potencialmente causadora de significativa degradação do meio ambiente (Schenini, 2005). De acordo com Schenini (2005), a exigência de Estudo de Impacto Ambiental (EIA) e do Relatório de Impacto no Meio Ambiente (Rima) para a implantação e o funcionamento de empresas particulares e a execução de obras pelo governo serve como inibidora da degradação ambiental. Por intermédio desses instrumentos jurídicos - EIA e Rima, as empresas e o governo iniciam o processo de licenciamento ambiental para suas obras. Outro marco da legislação, especialmente para setores como o de saneamento, é a Lei ${ }^{\circ} 9.433$, de 1997, que instituiu a Política Nacional de Recursos Hídricos. Essa lei regulamentou e estabeleceu critérios para o uso das bacias hidrográficas e a outorga pelo uso da água, com a criação do Sistema Nacional de Gerenciamento de Recursos Hídricos.

Para além da legislação, a gestão ambiental envolve práticas diversas, que podem ser classificadas em fases, etapas ou abordagens. Uma das primeiras contribuições nesse sentido foi elaborada por Donaire (1995), que realizou um estudo com o objetivo de entender por que e como a variável ambiental vinha sendo introduzida na estrutura organizacional, a partir de um modelo descrito por Ackerman e Bauer (1976), o qual indica as fases do envolvimento organizacional no processo de conscientização social das organizações. Donaire (1995) observou que havia similaridade com relação à variável ambiental, cuja inserção nas organizações obedecia a uma sequência de três fases: percepção, compromisso e ação.

a) $\mathrm{Na}$ fase da percepção, a cúpula administrativa entende a importância da variável ambiental, considera-a na política organizacional e percebe a necessidade de pessoal especializado, algo nem sempre percebido por todos os níveis e áreas da mesma maneira.

b) fase do compromisso é caracterizada pela contratação de assessoria especializada para lidar com a variável ambiental e apoiar a condução das ações. Busca-se disseminar o comprometimento quanto ao meio ambiente nos diversos níveis da organização.

c) A fase da ação pode ser percebida em organizações que buscam a excelência ambiental. Nesta situação, a organização é madura em relação à variável ambiental, que modifica processos e produtos e se torna presente em todos os níveis da estrutura e da cultura da organização.

Jabbour e Santos (2006), por sua vez, elaboraram uma taxonomia de três etapas para classificar a evolução da gestão ambiental nas empresas:

a) Especialização funcional - Nessa etapa, geralmente, é criada uma área funcional de meio ambiente na organização, cujo foco se concentra no controle de problemas ambientais que podem causar dificuldades para a alta administração no alcance da estratégia da empresa e a postura é reativa, ou seja, as respostas às mudanças no ambiente são lentas e raramente são proativas. Neste caso, a variável ambiental não é percebida como fator competitivo ou oportunidade de negócios futuros e as atividades são restritas às exigências de mercado e da legislação.

b) Integração interna - O meio ambiente não é tratado como fator estratégico, mas já é considerado pela alta administração como um dos objetivos da organização. Os objetivos costumam ser definidos sem participação do pessoal da área ambiental. Uma área específica e isolada costuma ser a responsável pela gestão ambiental, buscando ajustar o conteúdo dos programas e políticas à estratégia do negócio. As ações ambientais ainda são estritas às exigências de mercado e da legislação. A variável ambiental, ainda que utilizada no desenvolvimento de alguns produtos e processos, não é extensiva a toda a organização. As áreas ambientais e de produção trabalham juntas se for necessário desenvolver processos de Produção Mais Limpa ou introduzir produtos para um novo nicho de mercado. Organizações nessa etapa, em geral, atuam em ambiente empresarial não muito complexo e nem dinâmico.

c) Integração externa - Na terceira e última etapa, as atividades de gestão ambiental são integradas à estratégia central da organização. Neste estágio, a gestão ambiental, é percebida como vantagem competitiva e o meio ambiente como oportunidade de negócio. 
Os objetivos ambientais redefinem competências e responsabilidades em todos os níveis hierárquicos e os conhecimentos e as habilidades dos diversos especialistas da organização são integrados à tecnologia utilizada pela empresa, a fim de formar as competências essenciais da organização, havendo comunicação constante entre a área ambiental e as áreas de produção.

Já segundo Barbieri (2007), uma empresa pode atuar em relação às questões ambientais de acordo com três diferentes abordagens:

a) Controle da poluição - Nessa fase, a organização preocupa-se em atender à legislação e às pressões da comunidade. Suas ações são reativas e confinadas nas áreas poluidoras, visando corrigir pontualmente os efeitos negativos de suas atividades e produtos, sem alterar seus insumos e processos. A alta administração envolve-se esporadicamente nas questões ambientais e percebe-as como custo adicional.

b) Prevenção da poluição - Nessa fase, a organização busca usar os insumos de maneira eficiente e prevenir a poluição. Faz isso por meio de ações reativas e preventivas, com o envolvimento de diferentes áreas da empresa, usando tecnologia limpa e substituindo insumos degradantes. A alta administração tem envolvimento periódico e percebe a preservação do meio ambiente como possível redução de custos e aumento de produtividade.

c) Estratégica- Na última fase, a organização percebe a gestão ambiental como fonte de vantagem competitiva. $\mathrm{O}$ envolvimento da alta administração é permanente e sistemático e as atividades ambientais integram a cultura da empresa. É utilizada tecnologia limpa, as ações são corretivas, preventivas e antecipatórias e as soluções são de médio e longo prazo.

Essas classificações de fases ou abordagens à gestão ambiental serão referência para análise das práticas da empresa de saneamento Água Azul, cujo setor é apresentado a seguir.

\subsection{Empresas de saneamento básico no Brasil}

Saneamento básico é o conjunto de serviços, infraestruturas e instalações operacionais de abastecimento de água potável, esgotamento sanitário, limpeza urbana e manejo de resíduos sólidos, drenagem e manejo das águas pluviais urbanas (Brasil, 2007). Os serviços de saneamento prestados, de maneira eficiente e universal, são fundamentais para a qualidade de vida, a saúde pública, a longevidade das populações e a preservação do meio ambiente e o desenvolvimento de uma nação (Filho, Abreu \& Fernandes, 2008; Madeira, 2010). Apesar da reconhecida importância desse serviço, 900 milhões de pessoas em todo o mundo não têm acesso à água potável e, aproximadamente, 2,5 bilhões de pessoas não contam com saneamento básico adequado, conforme dados da Organização das Nações Unidas (ONU, 2010).

O saneamento básico no Brasil começou a ser estruturado nas décadas finais do século XIX. Inicialmente, o Estado concedeu as atividades a empresas estrangeiras, que realizavam as obras de rede e exploravam os serviços. Em 1971, o governo federal lançou o Sistema Nacional de Saneamento e institucionalizou o Plano Nacional de Saneamento, o Planasa, um instrumento para incentivar os estados a implantar sistemas de abastecimento de água e esgotamento sanitário nas cidades. A meta do Planasa era atender a $90 \%$ da população urbana com abastecimento de água de boa qualidade e 65\% com esgotamento sanitário até o ano de 1990 (Philippi Jr. \& Ogera, 2005). Foram então criadas 27 Companhias Estaduais de Saneamento Básico (CESB), constituídas como sociedades anônimas com controle estatal, cabendo-lhes a concessão dos sistemas de saneamento urbano (Philippi Jr. \& Ogera, 2005; Bier, Paulani \& Messenberg, 1988, 1988). Essas companhias eram também responsáveis pela gestão dos serviços de água e esgoto concedidos pelos municípios, em contratos com prazos de 20 a 25 anos. Até o final da década de 1980, mais de quatro mil municípios haviam concedido seus serviços às companhias estaduais (Philippi Jr. \& Ogera, 2005).

Na década de 1980, alterações no contexto político-econômico determinaram mudanças no 
setor. Os financiamentos, que eram taxados a baixo custo, tornaram-se caros, inviabilizando os investimentos. Em 1986, o Planasa foi extinto. Em 1988, na Constituição Federal, a competência dos serviços de saneamento básico foi novamente transferida ao município, podendo ser prestados diretamente ou sob o regime de concessão (Bier, Paulani \& Messenberg, 1988; Nozaki, 2007). Outra influência sobre o setor nesse período foi a emergência mundial da temática ambiental, repercutindo no próprio conceito de saneamento básico, por vezes redefinido como saneamento ambiental, enfatizando a prestação dos serviços com foco na preservação ambiental e na sustentabilidade.

Atualmente, os serviços de abastecimento de água e esgotamento sanitário são oferecidos pelas companhias estaduais, pelos municípios, por meio de administração municipal direta, ou autarquias, ou empresas públicas, podendo ser assistidos pela Fundação Nacional de Saúde (FNS) e por prestadores privados. Segundo dados do Sistema Nacional de Informações sobre Saneamento (SNIS), o país contava, em 2010, com noventa e seis prestadores municipais, vinte e três companhias estaduais e quinze prestadores privados (SNIS, 2010). Uma dessas companhias é a Água Azul, que passamos a abordar a seguir, com base na metodologia de pesquisa brevemente descrita.

\section{MÉTODO DE PESQUISA}

Esta pesquisa caracteriza-se como qualitativa, exploratória e descritiva (Godoy, 1995; Richardson, 1999), focalizando o estudo de um caso único, o da empresa aqui denominada Água Azul. Busca-se analisar certo fenômeno - a mudança organizacional em gestão ambiental - relativo a essa unidade social, descrevendo e explorando elementos que permitam compreender sua dinâmica, de modo denso, no contexto em que ocorre. O estudo de caso é justamente uma estratégia de pesquisa apropriada quando o pesquisador procura responder às questões como e porque certos fenômenos ocorrem, em seu contexto, em situações em que as fronteiras entre fenômeno e contexto não estão claramente estabelecidas e nas várias dimensões em que elas se apresentam (Godoy, 1995; Eisenhardt, 1989; Yin, 2005).

O caso é analisado longitudinalmente, desde a fundação da empresa, em 1979, até o ano de 2009, orientado pelas dimensões de conteúdo (o que mudou), contexto (porque mudou) e processo (como mudou) (Pettigrew, 1987) e por categorias de análise, classes de elementos com características comuns reunidos sob um nome genérico (Bardin, 2004). Para cada dimensão foram definidas três categorias, as quais surgiram da análise de relatórios na primeira fase do estudo. Tais categorias são apresentadas na figura 1 e serão detalhadas adiante, na apresentação dos dados da empresa e sua análise em cada período.

\begin{tabular}{|l|l|l|l|l|}
\hline \multicolumn{2}{|l|}{ Dimensão } & Categorias \\
\hline \multirow{3}{*}{ Contexto } & Interno & Acionistas e corpo diretivo & Características de desempenho & Tecnologia \\
\cline { 2 - 5 } & Externo & Legislação & Temática ambiental & Conjuntura \\
\hline Conteúdo & & Repertório & Perfil institucional & Principais obras \\
\hline Processo & & Investimentos & Alterações estruturais & Diretrizes de ação \\
\hline
\end{tabular}

Figura 1- Categorias de análise em cada dimensão do estudo

Fonte: Elaboração própria

Para a coleta, tratamento e análise dos dados, utilizou-se a abordagem de direct research, proposta por Mintzberg (1979) e Mintzberg e McHough (1985), que utiliza uma abordagem longitudinal de análise da evolução da organização ao longo de certo período histórico. Os estágios propostos pela direct research foram seguidos: 1) Coleta de dados básicos secundários; 2) Inferências e períodos; 3) Análise dos períodos; 4) Análise teórica.

A coleta de dados inicial se deu por meio da busca em relatórios anuais e de gestão emitidos pela empresa para divulgar as atividades desenvolvidas ao longo do ano ou ao final de um período de gestão, resoluções e organogramas da empresa, trabalhos técnicos, publicações, artigos científicos, dissertações, teses, legislação e regulamentações sobre o meio ambiente, recursos 
hídricos e o setor de saneamento. A etapa seguinte foi a obtenção dos dados primários, por meio de entrevistas que visavam verificar as informações obtidas com os dados secundários e enriquecer a análise por meio da captura de detalhes não abrangidos pelos documentos. Foram realizadas oito entrevistas semiestruturadas com funcionários da empresa e uma entrevista com um ex-presidente de órgão ambiental do estado no qual a empresa atua. A escolha dos entrevistados foi intencional. Com exceção do entrevistado externo, selecionaram-se pessoas com, pelo menos, vinte anos de atuação na organização, que tivessem conhecimento sobre sua história e as mudanças ocorridas desde os anos iniciais.

Durante a coleta de dados, certos eventos revelaram-se fundamentais para a compreensão das mudanças em gestão ambiental ao longo dos trinta e oito anos de existência da empresa. Esses eventos de transição foram reconhecidos como marcantes na história da organização em relação ao meio ambiente, levando à divisão em quatro períodos de análise, marcados por alterações na estrutura organizacional, os quais são apresentados na figura 2.

\begin{tabular}{|l|l|l|}
\hline Período & Anos & Evento de transição \\
\hline $1^{\circ}$ & 1971 a 1994 & Criação da Água Azul \\
\hline $2^{\circ}$ & 1995 a 2000 & Criação da Gerência de Recursos Hídricos e Meio Ambiente (GMA) \\
\hline $3^{\circ}$ & 2001 a 2005 & Criação da Assessoria de Meio Ambiente (AMA) \\
\hline $4^{\circ}$ & 2006 a 2009 & Criação da Superintendência de Meio Ambiente e Recursos Hídricos (SMA). \\
\hline
\end{tabular}

Figura 2 - Períodos analisados e eventos de transição

Fonte: Elaboração própria

Com os dados secundários sistematizados nas categorias de cada uma das dimensões e juntados às informações obtidas nas entrevistas (dados primários), considerando a definição dos períodos, foi possível caracterizar cada um deles por meio de um padrão de comportamento ambiental, identificando-se em qual fase ou etapa de gestão ambiental a organização se encontrava em cada um dos períodos considerados, de acordo com os estágios abordados por Barbieri (2007), Jabbour e Santos (2006) e Donaire (1995).

Entre as limitações da pesquisa, cabe destacar a dificuldade na observação de dados relativos às categorias de processo, algo admitido por Pettigrew (1987) como desafiador. Outra limitação refere-se às fontes de evidências, uma vez que não foi possível abarcar a diversidade e a amplitude de elementos e agentes envolvidos na análise da organização, ao longo de 38 anos, que contribuiriam para explicar as mudanças em gestão ambiental. Não foi explorada, por exemplo, a visão de agentes externos à organização, dada a opção, durante o trabalho de campo, de focalizar documentos e relatórios, bem como entrevistas com pessoas que atuaram na empresa por, pelo menos, vinte anos e um ex-presidente de órgão ambiental.

\section{CARACTERIZAÇÃo E ANÁlise DA GESTÃo AMBIENTAL EM QUATRo PERÍODOS}

Cada um dos períodos considerados na análise é detalhado a seguir, a partir das categorias das dimensões contexto, conteúdo e processo, apresentando-se os principais fatos ocorridos e as características relativas à gestão ambiental, enquadrando-as nas classificações propostas por Barbieri (2007), Jabbour e Santos (2006) e Donaire (1995).

\subsection{De 1971 a 1994 - Expansão do saneamento e chegada do tema ambiental}

Entre os anos de 1971 e 1994, a Água Azul iniciou e expandiu seus sistemas e redes a fim de cumprir as metas de saneamento básico da época, orientada pela função social de promover a saúde e o bem-estar da população atendida. No contexto interno, este período foi marcado pelo crescimento do número de ligações e sistemas e por constantes trocas na presidência da empresa, o que gerou instabilidade e descontinuidade de programas. A influência do contexto externo na organização foi balizada pelos dispositivos legais imputados às suas atividades e operações e aos 
problemas e crises econômicas vividas pelo país, gerando oscilações na obtenção de financiamentos. Não foi observada influência direta na organização das discussões e dos eventos mundiais sobre a temática ambiental ocorridos no período.

$\mathrm{Na}$ dimensão conteúdo, o objetivo principal manteve-se em cumprir a função social da empresa, focalizando, ao longo dos anos, o desafio de contribuir para o desenvolvimento social por meio do saneamento, além da melhoria do atendimento ao usuário. As obras, que no início do período, concentravam-se nas grandes cidades, passaram a ocorrer também em cidades menores. Com a obrigatoriedade do EIA e do Rima para as obras, foram necessárias alterações nos processos administrativos. Ocorreram as primeiras menções à preservação ambiental e ao meio ambiente, que apareceram em dois relatórios de gestão.

Em relação ao processo, o primeiro período caracterizou-se por modificações na estrutura organizacional, novas instalações, alterações no plano estratégico e diversidade de fontes de financiamento. A organização ainda não tinha representatividade em câmaras técnicas, comitês e programas ligados ao meio ambiente.

As categorias de análise em destaque nesse período foram Legislação e Temática Ambiental, da dimensão contexto externo; e a categoria Repertório, da dimensão conteúdo, ainda que a categoria Temática Ambiental tenha exercido pouca influência direta nas atividades organizacionais. Relativamente à gestão ambiental, nesse primeiro período, não foram encontradas ações concretas e formalizadas na Água Azul, mas apenas alguns termos presentes em relatórios de atividades e o foco no cumprimento da legislação ambiental vigente. As poucas mudanças em gestão ambiental foram motivadas por aspectos do ambiente externo, especialmente a legislação. A empresa esteve focada em expandir suas atividades, realizar obras, inaugurar sistemas de água e esgoto e sobreviver às oscilações econômicas constantes na época.

A fraca aproximação com as questões ambientais não era postura exclusiva da Água Azul. Neste período, as demais Companhias de Saneamento brasileiras, de acordo com um dos entrevistados, igualmente guiavam-se por metas de crescimento e expansão dos serviços, sem considerar a proteção ambiental. Segundo o Entrevistado A, as empresas de saneamento no período do Planasa foram criadas como empresas de engenharia para realizarem obras e alavancarem a infraestrutura do país, ignorando a necessidade de proteger vegetação ou nascentes de água para construir, algo que era comum a todo o setor de infraestrutura do país.

Analisando o comportamento da empresa em relação à gestão ambiental neste primeiro período com base nas abordagens de Barbieri (2007), Jabbour e Santos (2006) e Donaire (1995), temos:

a) Controle da poluição, de acordo com a tipologia de Barbieri (2007) - a postura da empresa era reativa, contemplava ações de correção e foi direcionada ao cumprimento da legislação vigente e à resposta aos questionamentos da sociedade e da mídia. Uma evidência da postura reativa consta do relatório de gestão 1991-1994, no qual a empresa justifica a aquisição de novos interceptores para evitar que os efluentes finais do esgoto degradassem o meio ambiente, após ter ocorrido vazamento de efluentes não tratados.

b) A empresa não se classifica em qualquer das etapas propostas por Jabbour e Santos (2006) - Não foi observada na Água Azul qualquer área funcional dedicada às atividades ambientais, tampouco postura preventiva em relação aos problemas ambientais, já que apenas corrigia problemas decorrentes da poluição.

c) As características apresentadas por Donaire (1995) nas três fases não condizem com a postura de ação da Água Azul em relação à variável ambiental, nesse primeiro período de análise. O tema meio ambiente sequer aparece no planejamento da alta direção.

\subsection{De 1995 a 2000 - Primeiros passos em gestão ambiental}

No segundo período, de 1995 a 2000, a Água Azul viveu inconstância interna e restrições quanto aos recursos para financiamento, o que não inviabilizou obras importantes. A empresa deu 
os primeiros passos no entendimento de seu papel ao trabalhar com recursos ambientais indispensáveis à existência humana frente à necessidade de minimizar os efeitos degradantes dos processos produtivos sobre o meio ambiente.

A análise do contexto interno permitiu observar que a empresa passou por momentos de instabilidade, provocadas pelas mudanças na presidência, que demonstraram sua suscetibilidade à influências políticas e partidárias, e pelo aumento da participação de uma empresa de energia elétrica no capital social da Água Azul. Em paralelo, obteve avanços em desempenho operacional, sobretudo pelo incremento no índice de abastecimento de água.

No contexto externo, destacam-se a criação da Agência Nacional de Águas (ANA) e dos dispositivos legais que regulamentaram o uso e a gestão dos recursos hídricos, e a Resolução 237/97 do Conama, de licenciamento ambiental. Fatores internacionais, como o Protocolo de Kyoto e a Carta da Terra, fortaleceram discussões sobre desenvolvimento sustentável e proteção ao meio ambiente, enquanto a conjuntura foi marcada pela estabilidade monetária e expansão do setor de saneamento, no início do período, e pela restrição a financiamentos e programa voltado à modernização do setor de saneamento, ao seu final.

$\mathrm{Na}$ análise do conteúdo, observou-se que a preocupação da empresa estava voltada para melhorias nos serviços e na qualidade de vida da população e para a recuperação financeira, que passou a ser requisito na obtenção de crédito junto a financiadores. A empresa realizou obras em cidades de todas as regiões, bem como parcerias e estudos para o uso mais eficiente e responsável das bacias hidrográficas.

$\mathrm{Na}$ dimensão processo, a preocupação com os recursos naturais apareceu com mais ênfase e foi possível observar ações direcionadas ao fortalecimento da área ambiental. Com a criação da Gerência de Recursos Hídricos e Meio Ambiente (GMA) e a participação em comitês e conselhos, a empresa formalizou na estrutura organizacional a preocupação ambiental e iniciou o processo de fortalecimento da imagem institucional perante a sociedade e aos órgãos fiscalizadores.

As mudanças na gestão ambiental no segundo período de análise foram observadas mais fortemente nas categorias da dimensão processo Alterações estruturais e Diretrizes de ação. Nestas, foi possível perceber mudanças no comportamento ambiental, com a alteração do organograma e a participação em comitês e conselhos. Entretanto, apesar do possível avanço ao criar uma gerência dedicada às questões ambientais, o tema meio ambiente restringia-se a ações desta gerência e as práticas ambientais que não eram contempladas nas estratégias e nos objetivos centrais da empresa.

A empresa mantinha-se voltada a sobreviver às oscilações, recuperar as finanças e obter bom desempenho operacional. Dados relativos ao perfil institucional e às diretrizes de ação mostram que a preocupação em relação ao meio ambiente concentrava-se em proteção às bacias hidrográficas e aos mananciais, que são fontes geradoras de água, recurso essencial para a Água Azul. Nos relatos dos entrevistados, ficou claro que, no período, a empresa mantinha a postura de controlar a poluição e atender minimamente à legislação ambiental. Seu objetivo era realizar mais obras no menor tempo possível.

Segundo as classificações dos autores referenciais para este estudo, no segundo período, o comportamento da Água Azul quanto à questão ambiental enquadra-se:

a) No controle da poluição (Barbieri, 2007) - O envolvimento da alta administração com questões ambientais restringiu-se à criação da área ambiental (GMA), que se manteve marginal em relação às estratégias da empresa. Não foi observado envolvimento das outras áreas com as questões ambientais. A preocupação da empresa estava em cumprir a legislação, sem alterar significativamente seus processos.

b) Na especialização funcional (Jabbour \& Santos, 2006) - Segundo os autores, essa etapa coincide com a criação da área funcional de meio ambiente na organização e isso pode ser observado na Água Azul pela criação da GMA. A postura da organização era reativa e limitada a controlar os problemas ambientais e cumprir a legislação por conta da atuação do Ministério Público e dos possíveis problemas que poderia causar à empresa. A 
variável ambiental não era percebida como vantagem competitiva e a reação da empresa em relação às mudanças ocorridas no contexto era lenta.

c) $\mathrm{Na}$ fase da percepção (Donaire, 1995) - A alta direção, apesar de não considerar a variável ambiental como oportunidade estratégica, passou a considerá-la na estrutura organizacional e criou uma gerência específica para cuidar das ações relativas ao meio ambiente, cedendo a argumentos e pressões de um grupo de funcionários.

\subsection{1 a 2005 - Amadurecimento e adaptações}

No terceiro período, a empresa procurou adotar nova postura institucional ao realizar mudanças na estrutura organizacional e ao executar ações ligadas ao meio ambiente. $\mathrm{O}$ contexto interno foi marcado por substituições na diretoria executiva, fim dos contratos de concessão assinados pelos municípios durante o Planasa, modernização das estações de tratamento e aquisição de produtos químicos menos degradantes. A nova postura em gestão ambiental permitiu certo diferencial no momento de obtenção de financiamentos externos.

No contexto externo, os dispositivos legais e um evento contribuíram para a regulamentação do setor de saneamento e para a preservação ambiental. Destaca-se o Decreto $n^{\circ} 5.445$, no qual o governo federal, em 2005, aderiu ao Protocolo de Kyoto, e à tramitação do Projeto de Lei 5296, que pretendia regulamentar o setor, estabelecendo diretrizes para os serviços públicos de saneamento básico e para a Política Nacional de Saneamento Básico.

A análise do repertório nos relatórios mostrou que a preservação ambiental se tornou um dos quatro pilares da missão da empresa, verificado, principalmente, em ações de preservação e recuperação do meio ambiente. A melhoria da qualidade da água de modo responsável, em termos ambientais, passou a integrar os objetivos, o meio ambiente passou a influenciar as diretrizes estratégicas e a logomarca da empresa mudou para incluir a cor verde. Estes elementos, entretanto, presentes no discurso formal da empresa, não vieram acompanhados de informações mais detalhadas que esclarecessem como a organização tornava o meio ambiente primordial em suas atividades. Não foi observada a adoção de algum Sistema de Gestão Ambiental, de metas ambientais a serem perseguidas ou indicadores de desempenho ambiental que pudessem evidenciar os avanços.

Os relatórios de 2001, 2002, 2003 e 2005 relataram ações ambientais, programas, projetos e obras, além do investimento em cursos para os técnicos da área ambiental e mostraram que a empresa buscava ter uma atitude ambientalmente mais responsável. Os relatórios deram destaque a termos, tais como gestão, educação ambiental, preservação ambiental, recursos hídricos, meio ambiente e compromisso.

$\mathrm{Na}$ análise do processo, as alterações no organograma e nas nomenclaturas das áreas refletiram, na estrutura organizacional, o discurso formalizado nos relatórios que demonstravam a Água Azul como organização preocupada com a preservação dos recursos naturais e que tem o meio ambiente como diretriz estratégica. Porém, não foram mencionadas mudanças em processos operacionais, mas apenas a aquisição de tecnologias menos degradantes.

As mudanças na gestão ambiental da Água Azul, nesse terceiro período, foram mais bem observadas nas categorias Repertório, da dimensão conteúdo, e nas categorias Alterações Estruturais e Diretrizes de Ação, da dimensão processo.

Como ocorreu no segundo período com a criação da GMA, as ações ambientais foram direcionadas para uma só área quando da criação da Consultoria de Gestão Ambiental (CGA). Esta, porém, diferente da GMA, possuía um rol de atribuições mais amplo de atividades técnicas e administrativas, com status de consultoria, e era diretamente subordinada à Diretoria da Presidência, o que facilitou sua visibilidade e ampliou sua atuação.

Diante dessas constatações, no terceiro período de análise, a Água Azul atuou na:

a) Prevenção da poluição em relação ao meio ambiente, conforme classificação de Barbieri (2007) - A diretoria executiva esteve periodicamente envolvida com as questões ambientais e 
definiu meio ambiente como uma das diretrizes estratégicas, ainda que mais visível no discurso oficial dos relatórios. Houve disseminação das atividades ambientais para outras áreas da empresa com a criação da CGA. A participação em conselhos e comitês expõe o esforço da empresa em demonstrar que está envolvida com a proteção ao meio ambiente, que é um agente ativo nas discussões, e que deseja influenciar o rumo dos debates.

b) Integração interna, à luz das etapas evolutivas descritas por Jabbour e Santos (2006) - O meio ambiente começou a ser tratado formalmente, no discurso, como um fator estratégico, mas não chegava a ser o foco competitivo principal da empresa. Nesta ocasião, o gerenciamento ambiental era ainda bastante guiado pelas regulamentações e sem a participação do pessoal da área ambiental na tomada de decisão. Os programas ambientais eram guiados pela estratégia da empresa, por exemplo, as políticas de recursos hídricos são essenciais para que a empresa obtenha a matériaprima fundamental para os seus serviços, e não o contrário, quando a escolha das políticas ambientais direciona a estratégia de negócio.

c) Fase do compromisso, quanto à incorporação da variável ambiental, de acordo com Donaire (1995) - A empresa criou assessoria específica para conduzir ações ambientais e fez mudanças que a conduziram para uma fase de mais comprometimento com o meio ambiente.

\subsection{6 a 2009 - Avanços e perspectivas}

No quarto período, a Água Azul avançou na busca pela nova postura institucional, o que se verificou nas alterações estruturais e na ampliação da participação em eventos, câmaras e conselhos ligados ao meio ambiente. No contexto interno, houve uma singularidade em relação aos períodos anteriores, o mesmo presidente esteve à frente da empresa durante todo o tempo analisado. $\mathrm{O}$ controle acionário sofreu modificação com a entrada de novo acionista, que integralizou capital correspondente a $15,03 \%$ das ações. Os indicadores de desempenho mostraram que a Água Azul avançou nos índices de abastecimento de água e atendimento de esgoto. Na tecnologia, foi possível observar o uso de diretrizes ambientais na perfuração de poços profundos para captação de água.

No contexto externo, enquanto a legislação, com a Lei 11.445, de 2007, traçou as diretrizes nacionais e a política para o saneamento básico com artigos que preencheram brechas deixadas por dispositivos anteriores, a conjuntura não foi favorável à Água Azul, que novamente enfrentou perdas de concessões de municípios que não renovaram os contratos.

$\mathrm{Na}$ análise do conteúdo, as obras, os projetos e programas desenvolvidos e as diversas expressões e frases que remetem ao desenvolvimento sustentável e à preservação ambiental encontradas nos relatórios anuais são evidências da busca da Água Azul para desempenhar suas funções com base nos preceitos da responsabilidade socioambiental e de cumprir a função de levar saúde e qualidade de vida à população. Porém, não se observou a utilização de indicadores de desempenho ambiental e a adoção de Sistema de Gestão Ambiental.

A dimensão processo demonstrou como a empresa executou as ações em busca da mudança da postura institucional iniciada no período anterior. A principal alteração ocorreu com a transformação da Consultoria de Gestão Ambiental (CGA) em Superintendência de Meio Ambiente e Recursos Hídricos (SMA). Além disso, a Água Azul ampliou participação em eventos, câmaras, conselhos e comitês.

As mudanças na gestão ambiental foram mais evidenciadas nas categorias Repertório e Perfil Institucional da dimensão conteúdo e Alterações Estruturais e Diretrizes de Ação da dimensão processo, pois, a partir delas, foi possível observar o que mudou e como mudou.

Na categoria Repertório, observou-se que a empresa definiu o meio ambiente como centro de todas as metas. O objetivo era difundir a responsabilidade e a necessidade de preservação dos recursos naturais por toda a empresa. Não foi observado, porém, como a empresa realizou na prática o discurso formalizado nos relatórios. No Perfil Institucional, as mudanças na gestão ambiental podem ser percebidas pela inserção de novos projetos e programas ambientais executados.

$\mathrm{Na}$ categoria das Alterações Estruturais, a nova postura institucional de colocar o 
desenvolvimento sustentável no centro de todas as metas foi favorecida com a mudança no organograma que elevou a área ambiental ao status de superintendência e ampliou seu escopo de atuação. Na categoria Diretrizes de Ação, percebeu-se aumento das ações ambientais promovidas pela empresa por meio da participação junto aos órgãos e conselhos ambientais. Diante dessa situação, o comportamento da Água Azul frente às questões ambientais pode ser considerado:

a) Como combinação de características das fases de prevenção da poluição e estratégica, de acordo com a classificação de Barbieri (2007) - A alta administração se envolveu mais de perto com as questões ambientais ao promover mudanças na estrutura organizacional. A empresa utilizou insumos menos degradantes no tratamento da água; seguiu diretrizes ambientais para a perfuração de poços, por meio de projetos e programas, atuou de maneira mais corretiva e preventiva em relação aos problemas ambientais e ampliou a participação na elaboração de minutas de leis, projetos de recursos hídricos e junto a conselhos e câmaras. Isso permitiu uma vantagem competitiva por possibilitar à empresa inserir-se nas discussões e decisões sobre o meio ambiente e obter novos financiamentos.

b) Na fase da integração externa, com ressalvas, na abordagem de Jabbour e Santos (2006) - O desenvolvimento sustentável passou a figurar como meta formal, a empresa passou a agir proativamente e a perceber a gestão ambiental como vantagem competitiva. As ressalvas aparecem, pois não foi possível observar como a Água Azul efetivou o desenvolvimento sustentável em suas metas. A empresa não possui indicadores que monitorem a imagem frente à sociedade e aos órgãos ambientais e não foi percebida a preservação ambiental como algo disseminado na cultura organizacional. Há, portanto, contradição entre o comportamento formalizado e as práticas da empresa. Não foi observado que a empresa perceba o meio ambiente como uma oportunidade de negócio e que defina competências e responsabilidades a partir de objetivos ambientais.

c) Em transição entre a fase do compromisso e ação, de acordo com etapas de Donaire (1995) - A empresa está consciente quanto à sua responsabilidade com o meio ambiente e os recursos ambientais, considera as variáveis ambientais na estrutura organizacional e busca por meio de programas, projetos e participação em conselhos e comitês, realizar ações concretas de compromisso com o meio ambiente. Entretanto, não é percebido que busque a excelência ambiental nem que a importância do meio ambiente esteja disseminada na cultura organizacional.

A figura 3 sintetiza as categorias de análise que se mostraram mais relevantes para compreender as mudanças organizacionais em gestão ambiental em cada período, bem como apresenta a classificação da gestão ambiental segundo as tipologias propostas pelos autores utilizados como referência para a análise.

\begin{tabular}{|c|c|c|c|}
\hline \multirow{2}{*}{ Período } & \multirow[t]{2}{*}{$\begin{array}{l}\text { Categorias mais relevantes para } \\
\text { análise da gestão ambiental }\end{array}$} & \multicolumn{2}{|c|}{$\begin{array}{l}\text { Classificação de acordo com as tipologias propostas } \\
\text { pelos autores }\end{array}$} \\
\hline & & \begin{tabular}{|l|l|} 
Barbieri (2007) Jabbour e Santos (2006) \\
\end{tabular} & Donaire (1995) \\
\hline $\begin{array}{l}\left.1^{\circ}\right) 1971 \text { a } 1994 \text { Expansão } \\
\text { do saneamento e chegada do } \\
\text { tema ambiental }\end{array}$ & $\begin{array}{l}\text { Legislação } \\
\text { Repertório } \\
\text { Temática ambiental }\end{array}$ & \begin{tabular}{|l|l|}
$\begin{array}{l}\text { Controle } \\
\text { poluição }\end{array}$ & daNão se verifica \\
\end{tabular} & Não se verifica \\
\hline $\begin{array}{l}\left.2^{\circ}\right) 1971 \text { a } 1994 \text { Expansão } \\
\text { do saneamento e chegada do } \\
\text { tema ambiental }\end{array}$ & $\begin{array}{l}\text { Alterações } \\
\text { Diretrizes de Ação }\end{array}$ & \begin{tabular}{l|l} 
da Especialização \\
funcional
\end{tabular} & Percepção \\
\hline $\begin{array}{lr}\left.3^{\circ}\right) \quad 2001 \quad \text { a } & 2005 \\
\text { Amadurecimento } & \mathrm{e} \\
\text { adaptações } & \\
\end{array}$ & $\begin{array}{l}\text { Repertório } \\
\text { Alterações estruturais } \\
\text { Diretrizes de ação }\end{array}$ & $\begin{array}{l}\text { Prevenção daIntegração interna } \\
\text { poluição }\end{array}$ & Compromisso \\
\hline $\begin{array}{l}\left.4^{\circ}\right) 2006 \text { a } 2009 \\
\text { Avanços e perspectivas }\end{array}$ & $\begin{array}{l}\text { Repertório; Perfil institucional; } \\
\text { Alterações } \\
\text { Diretrizes de ação }\end{array}$ & $\begin{array}{l}\text { daIntegração externa, com } \\
\text { eressalvas }\end{array}$ & $\begin{array}{l}\text { Compromisso } \\
\text { ação }\end{array}$ \\
\hline
\end{tabular}

Figura 3 - Categorias mais relevantes e classificação da gestão ambiental em cada período

Fonte: Elaboração própria

Revista de Gestão Social e Ambiental - RGSA, São Paulo, v. 7, n. 2, p. 20-36, maio/ago. 2013. 


\section{CONSIDERAÇÕES FINAIS}

Este estudo permitiu perceber diversas mudanças organizacionais em gestão ambiental na empresa de saneamento Água Azul ao longo dos trinta e oito anos compreendidos na análise. Essas mudanças mostram avanços na postura da empresa em relação às questões ambientais, embora a temática não tenha sido plenamente incorporada à suas práticas e à sua cultura organizacional. $\mathrm{E}$ ainda que, a rigor, a empresa não adote qualquer modelo e/ou sistema de gestão ambiental elaborado, com metas e indicadores que reflitam as várias áreas organizacionais e que permitam monitoramento.

A empresa buscou promover ações no sentido de consolidar nova postura institucional que vislumbrava colocar o meio ambiente entre os objetivos e as metas prioritárias. Para isso, realizou alterações no organograma e elevou o status da área ambiental a uma superintendência, buscou atender à legislação ambiental, mudou a logomarca inserindo a cor verde, dedicou capítulos nos relatórios para relatar as atividades ligadas ao meio ambiente e recursos hídricos, realizou programas e projetos ambientais, ampliou a participação em conselhos, comitês e câmaras e, com isso, aproximou-se dos órgãos ambientais.

Entretanto, a questão ambiental não chegou a ocupar o centro das metas da empresa e a ser incorporada à cultura organizacional. Foi apenas formalizada nos relatórios e percebida em elementos como logomarca, relatórios e alterações estruturais. A mudança de postura institucional pareceu ter sido construída artificialmente e a partir mais de interesses econômicos e políticos localizados do que de interesses característicos de uma nova postura em relação ao meio ambiente, reflexão essa que remete à relevância da compreensão das organizações como sistemas políticos. Esta é uma das contribuições do estudo desse caso para o conhecimento teórico sobre mudança organizacional, o reforço à relevância dos elementos e atores políticos que as influenciam.

$\mathrm{O}$ caso estudado mostra, também, uma das faces do movimento ambientalista pelo mundo, que faz com que certas ações ambientais deixem de ser diferenciais de mercado para serem obrigações, impostas por mudanças na legislação e na sua aplicação. Essas novas exigências são fruto de mudanças de valores, da existência de novas formas de expressão de interesses políticoinstitucionais, que afetam a postura de consumidores, da sociedade, dos mercados e dos governos. Apesar dessas mudanças no contexto geral, sua repercussão nas práticas organizacionais pode ser limitada ou superficial, como ficou evidente no estudo.

No caso das empresas de saneamento, uma particularidade é o fato de lidarem diretamente com recursos ambientais e delas ser esperada exemplaridade para outros setores quanto à postura de responsabilidade ambiental. Outra particularidade é a limitação das possibilidades de influência direta dos consumidores sobre as práticas da empresa, uma vez que não há opção em escolher outras empresas para prestarem os serviços de água e esgoto.

A realização deste estudo mostrou a pertinência da relação entre o modelo contextualista de processos de mudança de Pettigrew (1987) e diferentes tipologias de gestão ambiental, permitindo considerar diversas variáveis, embora esta tarefa seja sempre parcial e limitada, pela própria complexidade dos processos de mudança.

\section{REFERÊNCIAS}

Ackerman, R., \& Bauer, R. (1976) Corporate social responsiveness: the modern dilemma. Virginia: Reston.

Alperstedt, G. D. (2000) Adaptação estratégica em organização universitária: um estudo de qualidade na Universidade do Sul de Santa Catarina. 2000. Tese. (Doutorado em Engenharia de Produção). Florianópolis: Universidade Federal de Santa Catarina. 
Andion, M. C., \& Serva, M. (2006) Teoria das organizações e a nova sociologia econômica: um diálogo interdisciplinar. Revista de Administração de Empresas, 46 (2), 10-21.

Barbieri, J. C. (2007) Gestão ambiental empresarial: conceitos, modelos e instrumentos. (2a ed.). São Paulo: Saraiva.

Bardin, L. (2004) Análise de conteúdo. (3 ed.). Lisboa: Edições 70.

Bertalanffy, L. V. (1977) Teoria geral dos sistemas. Petrópolis: Vozes.

Bier, A. G., Paulani, L. M., \& Messenberg, R. P.(1988) A crise do saneamento no Brasil: reforma tributária, uma falsa resposta. Pesquisa e Planejamento Econômico, 18 (1), 161-96.

Brasil (1981). Lei $n^{\circ}$ 6.938, de 31 de agosto de 1981. Dispõe sobre a Política Nacional do Meio Ambiente, seus fins e mecanismos de formulação e aplicação, e dá outras providências. Recuperado em: 05.out.2010, de: < http://www.planalto.gov.br>.

Brasil (2007). Lei $n^{o} 11.445$, de 05 de janeiro de 2007. Estabelece diretrizes nacionais para o saneamento básico [...] e dá outras providências. Recuperado em: 5 out.2010, de: <http://www.planalto.gov.br>. .

Campos, L. M. S., \& Melo, D. A. (2008) Indicadores de desempenho dos Sistemas de Gestão Ambiental (SGA): uma pesquisa teórica. Revista Produção, 18 (3), 540-55.

Clegg, S. (1998) Organizações modernas. Celta: Oeiras.

Dias, R. (2009) Gestão ambiental: responsabilidade social e sustentabilidade. São Paulo: Atlas.

Donaire, D. (1995) Gestão ambiental na empresa. São Paulo: Atlas.

Duncan, R. B. (1972) Characteristics of organizational environments and perceived environmental uncertainty. Administrative Science Quartely, 17 (3), 313-27

Eisenhardt, K. (1989) Building theories from case study research. The Academy of Management Review, 14 (4), 532-50.

Feuerschütte, S. G. (1997) Cultura organizacional e dependências de poder: a mudança estrutural em uma organização do ramo de informática. Revista de Administração Contemporânea, 1 (2), 7395.

Filho, J. C., Abreu, M. C. S., \& Fernandes, M. R. C. (2008) Análise da gestão ambiental nas companhias estaduais de saneamento básico. Revista Alcance, 15 (3), 322-42.

Godoy, A. (1995) Pesquisa qualitativa: tipos fundamentais. Revista de Administração de Empresas, 35 (3), 20-9.

Grey, C. (2004) O fetiche da mudança. Revista de Administração de Empresas, 44 (1), 10-25.

Guimarães, P.C. (1995) Estratégias empresariais e instrumentos econômicos de gestão ambiental. Revista de Administração de Empresas, 35 (5), 72-82.

Hernandes, J. M. C., \& Caldas, M. P. (2001) Resistência à mudança: uma revisão crítica. Revista de Administração de Empresas, 41 (2), 31-45.

Jabbour, C. J., \& Santos, F. C. (2006) The evolution of environmental management within organizations: toward a common taxonomy. Environmental Quality Management, (16), 43-59.

Katz, D., \& Kahn, R. (1987) Psicologia social das organizações. São Paulo: Atlas.

Madeira, R. F. (2010) O setor de saneamento básico no Brasil e as implicações do marco regulatório para a universalização do acesso. Revista do BNDES, 33, 123-54. 
Mello, R. B. (1997) O estudo da mudança estratégica organizacional em pequenas empresas de construção de edificações: um caso em Florianópolis. Dissertação. (Mestrado em Engenharia da Produção). Florianópolis: Universidade Federal de Santa Catarina.

Mintzberg, H. (1979) An emerging strategy of "direct" research. Administrative Science Quartely, 24 (4), 582-89.

Mintzberg, H., \& Mchugh, A. (1985) Strategy formation in an adhocracy. Administrative Science Quarterly, 30 (1), 160-97.

Mintzberg, H., \& Westley, F. (1992) Cycles of organizational change. Strategic Management Journal, 13 (1), 39-59.

Moura, L. A. A. (2002). Qualidade e gestão ambiental. São Paulo: Juarez Oliveira.

Nobre, M., \& Amazonas, M. C. (org.) (2002) Desenvolvimento sustentável: a institucionalização de um conceito. Brasília: Ed.Ibama, 21-6.

Nozaki, V. T. (2007) Análise do setor de saneamento básico no Brasil. Dissertação. (Mestrado em Economia Aplicada). Ribeirão Preto: Universidade de São Paulo.

Organização das Nações Unidas (ONU) (2010). ONU Água. Disponível em: <www.onubrasil.org.br >. Acesso em: 17 out. 2010.

Pettigrew, A. (1987) Context and action in the transformation of the firm. Journal of Management Studies, 24 (6), 649-70.

(3), 267-92.

(1990) Longitudinal field research on change: theory and pratice. Organization Science 1

Philippi Jr. A., \& Ogera, R. C. (2005) Gestão dos serviços de água e esgoto nos municípios de Campinas, Santo André, São José dos Campos e Santos no período de 1996 a 2000. Engenharia Sanitária e Ambiental, 10 (1), 72-81.

Richardson, R. J. (1999) Pesquisa social: métodos e técnicas. São Paulo: Atlas.

Robbins, S. P. (2006) Comportamento organizacional. São Paulo: Makron Books.

Schenini, P. C. (2005) Gestão empresarial sócio ambiental. Florianópolis: NUPEGEMA.

P.C. (2000) Avaliação dos padrões de competitividade à luz do desenvolvimento sustentável: o caso da indústria Trombini de Papel e Embalagens S/A em Santa Catarina. Revista de Ciências da Administração, 2 (4), 55-64.

Sistema Nacional de Saneamento Básico (SNIS) (2010) Diagnóstico dos serviços de água e esgotos (2012). Recuperado em: 15.out.2010, de: http://www.snis.gov.br.

Valle, C. E. (1995) Qualidade ambiental: o desafio de ser competitivo protegendo o meio ambiente. São Paulo: Pioneira.

Weick, K. E., \& Quinn, R. E. (1999) Organizational change and development. Annual Review of Psychology, 50 (1), 361-386.

Wood. Jr., T. (1995) Mudança organizacional: aprofundando temas atuais em administração de empresas. São Paulo: Atlas.

Yin, R. K. (2005) Estudo de caso: planejamento e métodos. (3a ed.). Porto Alegre: Bookman.

Data da submissão: 25/09/2012

Data da publicação: 30/08/2013 